\title{
A!
}

This is an electronic reprint of the original article.

This reprint may differ from the original in pagination and typographic detail.

Climente-Alarcon, Vicente; Sundaria, Ravi; Panchal, Jay; Arkkio, Antero

\section{Simulation of an induction motor's rotor after connection}

Published in:

IEEE CEFC 2016 - 17th Biennial Conference on Electromagnetic Field Computation

DOI:

10.1109/CEFC.2016.7815984

Published: 12/01/2017

Document Version

Peer reviewed version

Please cite the original version:

Climente-Alarcon, V., Sundaria, R., Panchal, J., \& Arkkio, A. (2017). Simulation of an induction motor's rotor after connection. In IEEE CEFC 2016 - 17th Biennial Conference on Electromagnetic Field Computation [7815984] IEEE. https://doi.org/10.1109/CEFC.2016.7815984

This material is protected by copyright and other intellectual property rights, and duplication or sale of all or part of any of the repository collections is not permitted, except that material may be duplicated by you for your research use or educational purposes in electronic or print form. You must obtain permission for any other use. Electronic or print copies may not be offered, whether for sale or otherwise to anyone who is not an authorised user. 
This is the accepted version of the original article published by IEEE.

(C) 2016 IEEE. Personal use of this material is permitted. Permission from IEEE must be obtained for all other uses, in any current or future media, including reprinting/republishing this material for advertising or promotional purposes, creating new collective works, for resale or redistribution to servers or lists, or reuse of any copyrighted component of this work in other works. 


\title{
Simulation of an Induction Motor's Rotor after Connection
}

\author{
Vicente Climente-Alarcon ${ }^{1}$, Ravi Sundaria ${ }^{1}$, Jay Panchal ${ }^{1}$ and Antero Arkkio ${ }^{1}$ \\ ${ }^{1}$ Aalto University, Department of Electrical Engineering and Automation, Espoo, FINLAND
}

\begin{abstract}
Transients have proven to be a specially demanding operation mode for rotor cages in induction motors. The combination of thermal and mechanical stresses causes damage in weak points of the secondary circuit of these machines. A multiphysics computation may shed some light into the conditions under faults such as broken bars develop.

Index Terms-Induction motors, rotors, electromagnetic transients, magnetomechanical effects.
\end{abstract}

\section{INTRODUCTION}

Transients in induction motors have proven especially damaging for the rotor cage [1]. Frequent startups or stall periods of large units cause heavy thermal and mechanical stresses that in addition to structural or manufacturing weak spots develop into breakages of this secondary circuit [2].

Fatigue tests [3] and analytical calculations [4] have been the traditional methods for studying the development of this fault, since the complexity of a Finite Element electromagnetic, thermal and mechanical computation was too big to be carried out. In [3] FEM was used to obtain the speed, and hence the inertial forces during the acceleration of an induction's motor rotor in a startup transient. Separately, the effects of such forces were imposed on a mesh simulating a rotor bar joint to the end ring. Since no thermal effects were considered, the simulation did not correspond to experimental data. Another approach is considered in [4] in which analytical expressions are used to model the skin effect in the rotor bar during stall conditions, as well as its thermal and mechanical (thermal expansion) consequences.

However, if the results are to have impact on design and fault evolution modelling (prognosis) more detailed computations are needed. 3D FE is mandatory if phenomena as interbar currents are taken into account. Thus, this work presents the $3 \mathrm{D}$ electromagnetic and mechanical computation of a rotor cage during the first instants after connection. In order to reduce the computational needs, a value of the magnetic vector potential is imposed on the rotor iron surface, thus not being simulated the stator.

\section{APPROACH FOLLOWED}

In this case ELMER software is used, which employs an AVA formulation based in the magnetic vector potential A $(\boldsymbol{B}=\operatorname{rot}(\boldsymbol{A}))$ and scalar potential $\mathrm{V}$. This allows a direct coupling of the 2-D to the 3-D field solution since a unique field distribution within the rotor can be obtained by setting the normal component of flux density on its boundaries along the normal component of the current density [5]. Following [6], the normal component of $\mathbf{B}$ is imposed by specifying the tangential component of $\mathbf{A}$ on the boundaries. A sinusoidal distribution having an average amplitude similar to the one obtained by 2D FE computation for the same motor is used, moving around the rotor surface at a frequency of $50 \mathrm{~Hz}$. Magnetic and electric insulation is imposed on the external boundaries of air surrounding the end rings' regions.

For the mechanical computation, the movement at both ends of the rotor is limited by setting spring boundary conditions on the limiting surfaces. The average displacement in the three Cartesian axis is computed. 1e-4 s time steps are used to simulate the first 2.5 cycles of the transient.

\section{RESULTS}

Fig. 1 shows currents induced in the shaft next to both end rings. The mechanical load of the fully enclosed skewed bars on the rotor surface is also depicted.

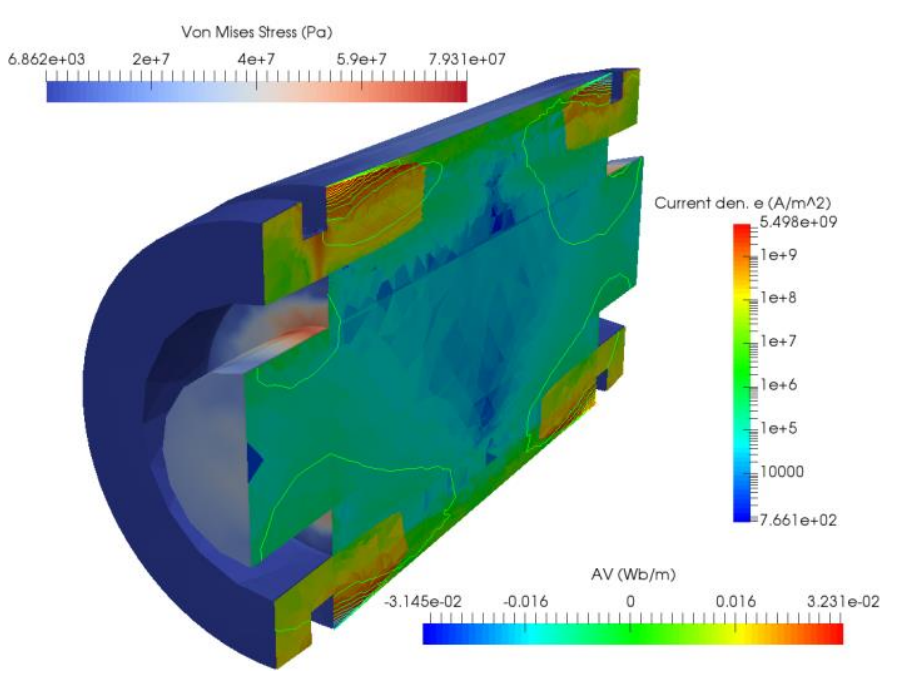

Fig. 1. Von Mises stress (rotor surface), elementary current density (slice) and magnetic vector potential (contour) of the damaged rotor after the simulation $(50 \mathrm{~ms})$. The increase of current density on the hot spot is shown in the upper part of the forward end ring.

\section{REFERENCES}

[1] M. Hodowanec, W. R. Finley, "Copper versus aluminum-which construction is best? [induction motor rotors]," IEEE Ind. Appl. Magazine, Vol. 8, 2002, pp. 14-25.

[2] J. Faiz; B. M. Ebrahimi, "A new pattern for detecting broken rotor bars in induction motors during start-up," IEEE Trans. Magn., vol. 44, no. 12, Dec. 2008

[3] M. F. Cabanas et Al., "Analysis of the fatigue causes on the rotor bars of squirrel cage asynchronous motors: Experimental analysis and modelling of medium voltage motors," in Proc. SDEMPED, 2003, pp. $247-252$.

[4] C. D.Pitis, "Thermo-mechanical stresses of the squirrel cage rotors in adverse load conditions," in Proc. ISEI, 2008, pp. 579-585, Vancouver, BC, Canada.

[5] O. Biro, "Edge element formulations and eddy current problems," Comput. Methods in Appl. M., vol. 169, no. 3-4, pp. 391-405, 1999.

[6] P. Handgruber, A. Stermecki, O. Biro, A. Belahcen, E. Dlala, "3-D eddy current analysis in steel laminations of electrical machines as a contribution for improved iron loss modelling," IEEE Trans. Ind. Appl., vol. 49, no. 5, pp. 2044-2052, 2013. 